\title{
Calcite Precipitation at Cement-Bentonite Interface. Part 1: Effect of Carbonate Admixture in Bentonite
}

\author{
Kenichiro Nakarai ${ }^{*}$, Masahito Shibata ${ }^{2}$, Hiroyuki Sakamoto ${ }^{3}$, Hitoshi Owada ${ }^{4}$ and \\ Georg Kosakowski ${ }^{5}$
}

\begin{abstract}
Calcium leaching from cementitious materials into bentonite is a key process for the long-term alteration of cement-clay interfaces of engineered barrier systems. Strong chemical gradients between cement and clay drive the precipitation of minerals such as calcium silicate hydrate $(\mathrm{C}-\mathrm{S}-\mathrm{H})$ and calcite. To analyze the mineralogical and porosity evolution at the cement-clay interface, composite specimens consisting of cement paste and bentonite mixed with various amounts of sodium carbonate were subjected to immersion and chloride migrations tests and were investigated by electron probe micro-analysis (EPMA), thermogravimetry/differential thermal analysis (TG-DTA), and X-ray diffraction (XRD) after 4-20 months of immersion. The results show that adding sodium carbonate to the bentonite enhanced the formation of calcite in the form of a surface layer on the cement paste. This suggests pore clogging at the interface and implies the existence of a threshold amount of carbonate addition above which pore clogging occurs. This is the first of two papers; the accelerated evolution of the samples in the presence of an electrical field is discussed in the second paper.
\end{abstract}

\section{Introduction}

The safe management and disposal of waste in general and specifically of toxic and radioactive waste is of critical importance for maintaining a safe and sustainable society (Lang-Lenton León 2001). The designs of waste repositories vary depending on the type of waste and the national regulations; however, the design should always follow international standards for safe disposal (IAEA 2011).

In the case of radioactive waste, the majority of designs utilize significant quantities of cement-based materials for constructing access galleries, storage cells, concrete plugs, and engineered barriers as well as for backfilling voids (Glasser and Atkins 1994; Metcalfe and

${ }^{1}$ Professor, Hiroshima University, Civil and Environmental Engineering Program, 1-4-1 Kagamiyama, Higashi-Hiroshima-shi, Hiroshima 739-8527, Japan. *Corresponding author,

E-mail: nakarai@hiroshima-u.ac.jp

${ }^{2}$ Research Engineer, Taiheiyo Consultant Co. Ltd., Electric and Nuclear Power Technology Department, 2-4-2, Ohsaku, Sakura-shi 285-0802, Japan.

${ }^{3}$ General Manager, Taiheiyo Consultant Co. Ltd., Electric and Nuclear Power Technology Department, 2-4-2, Ohsaku, Sakura-shi 285-0802, Japan.

${ }^{4}$ Manager, Radioactive Waste Management Funding and Research Center, Research and Development of Geological Disposal Barrier System, 6-4, Akashicho, Chuo-Ku, Tokyo 104-0044, Japan.

${ }^{5}$ Senior Scientist, Paul Scherrer Institute, Laboratory for Waste Management, Forschungsstrasse 111, 5232 Villigen PSI, Switzerland.
Walker 2004). In many design concepts, clay materials such as bentonite are also used to seal access galleries and engineered barriers (Pusch 1992; Metcalfe and Walker 2004; Sugita et al. 2007). Furthermore, deep geological repositories are sometimes located in clay host rock (Alexander and McKinley 2007).

Because of the large geochemical differences between cement and clay, the long-term evolution of clay-cement interfaces is an active area of research (Gaucher and Blanc 2006; Gaucher et al. 2009; Savage 2013; Marty et al. 2015; Luraschi et al. 2020). The chemical gradient can cause the dissolution of primary minerals in both materials and induce the precipitation of secondary minerals near the interface. Mineralogical changes induce changes in porosity, transport parameters, and mechanical properties, and can therefore compromise or enhance the functionality of clay and cement materials.

Early experimental studies on clay-cement contacts utilized batch experiments to investigate the evolution of clay powder or compacted clay samples in alkaline solutions (Gaucher and Blanc 2006). More recently, experimental investigations have focused on examining the interactions between hardened cement/mortar/concrete and compacted clay, including mass transport processes across the cement-clay interface (Dauzeres et al. 2010; Fernández et al. 2016; Yamaguchi et al. 2016; Balmer et al. 2017; Luraschi et al. 2020).

Long-term in-situ experiments in underground research laboratories (URLs) on cement-clay interactions have also been conducted, for example in Mol (Belgium) (Read et al. 2001), Tournemire (France) (Tinseau et al. 2006; Gaboreau et al. 2011), Bure (France) (Gaboreau et al. 2012), Grimsel (Switzerland) (Fernández et al. 2017) and Mont Terri (Switzerland) (Jenni et al. 2014; Mäder et al. 2017). These long-term experimental studies have 
revealed the precipitation of secondary minerals such as calcium silicate hydrate $(\mathrm{C}-\mathrm{S}-\mathrm{H})$, magnesium silicate hydrate (M-S-H), calcite (Gaboreau et al. 2012; Fernández et al. 2017; Mäder et al. 2017), and gypsum (Gaboreau et al. 2012) near the cement-clay interface and corresponding reduction in porosity. Previous laboratory and field experiments have revealed that the typical extensions of porosity changes at cement-clay interfaces were a few hundred micrometers to a few millimeters in a few years (Jenni et al. 2014; Luraschi et al. 2020). Longer experiments with interaction times greater than 10 years showed detectible porosity changes up to 1-2 cm from the interface (Gaboreau et al. 2020, 2011). Larger changes were common in the cement material. While porosity was often reduced near the interface, porosity further away from the interface increased owing to the dissolution of hydrated cement phases. However, unambiguous conclusions regarding the mechanism of pore clogging have not yet been identified to date.

It is impossible to experimentally assess the very long-term evolution of cement-clay interfaces as part of the engineered barrier system for the lifetime of a deep geological repository. Computer simulations are frequently used to predict the evolution of chemical conditions and material properties in deep geological repositories. Such predictions require a thorough understanding of the chemical reactivity of materials influenced by the transport of reactants (Seigneur et al. 2019). Process-based computer models are often used to analyze laboratory and field experiments by testing alternative processes and scenarios. However, experiments can be used to calibrate or validate the assumptions in predictive computer simulations. Following the development of a calcium-leaching model for cement-based materials (Bentz and Garboczi 1992; Buil et al. 1992; Yokozeki et al. 2003; Nakarai et al. 2006a), reactive transport modeling of cement-clay interactions has been conducted in numerous studies (van der Lee and De Windt 2001; Yokozeki et al. 2004; Nakarai et al. 2006b; Berner et al. 2013; Kosakowski and Watanabe 2014; Liu et al. 2014; Blanc et al. 2015; Marty et al. 2015). Nearly all numerical models showed strong porosity reduction and even pore clogging in response to the precipitation of secondary minerals, mainly $\mathrm{C}-\mathrm{S}-\mathrm{H}$ and/or calcite, near the cement-clay interface. The main mechanism underlying these changes involves the creation of dissolution fronts on both sides of the interface due to the strong contrast in $\mathrm{pH}$ between cement and clay pore waters. In the pore water of cement-based materials, calcium and hydroxide in equilibrium with hydrated cement phases are consumed near the interface by reactions with silicon or carbonate that originates from the clay. The migration of hydroxide from the cement into the clay increases the $\mathrm{pH}$, giving rise to the so-called $\mathrm{pH}$ plume, and enhances the dissolution of $\mathrm{SiO}_{2}$ and clay minerals. These changes, in turn, result in the release of silica, which also diffuses toward the interface from the clay compartment and contributes to secondary $\mathrm{C}-\mathrm{S}-\mathrm{H}$ formation. In addition, carbonate concentrations are generally higher in clay pore waters with intermediate $\mathrm{pH}$ than in those with high $\mathrm{pH}$; hence, calcite formation is observed in the latter. Although the calculated mineralogical evolution qualitatively agrees with experimental data, the calculated clogging times often depend on the discretization of the modeling domain and the parametrization of kinetic control of mineral precipitation/dissolution (Marty et al. 2009; Hayek et al. 2011, 2012). At the clogging times, the mineralogical alteration depth in the clay barrier from the interface with cement significantly varies, for example, from $1 \mathrm{~mm}$ to $20 \mathrm{~cm}$ (Marty et al. 2009).

Experimental studies reported to date have shown that the precipitation of carbonates, pore structure, and pore size distribution change significantly during concrete carbonation (Patel et al. 1985; Ngala and Page 1997; Šavija and Luković 2016). The type of cement material has a strong impact on the consequences of carbonation; it is expected that, as a consequence of carbonation, the porosity of cement paste might change. In their review, Šavija and Luković concluded that the porosity decreases for Portland cement paste and concrete while the porosity increases for blended cement paste as a result of carbonation (Šavija and Luković 2016). Similar observations have been reported for carbonate precipitation in soils (Bronick and Lal 2005). Furthermore, the bio-mediated calcite precipitation method accelerates the precipitation of calcite, and has been used to improve the mechanical properties of soils (Gollapudi et al. 1995; De Muynck et al. 2010; DeJong et al. 2010; Ho et al. 2018) and to repair cracks in concrete (Wu et al. 2012; Al-Salloum et al. 2017; Huynh et al. 2019).

Current state-of-the-art developments regarding the understanding of chemical and pore-scale processes that control the precipitation in porous media have been summarized recently in two review papers (Putnis 2015; Stack 2015). These reviews highlighted some key advances, including the detailed study on calcite precipitation in small pores, which was conducted using a hydrogel with a diffusive transport setup (Nindiyasari et al. 2014), where the importance of pore size on the precipitation process was demonstrated. Currently, however, the more complex interplay between pore size, surface charges, solute transport, and precipitation kinetics remains poorly understood. In addition, although fundamental investigations of simple systems have been conducted using both experimental and numerical techniques (Tartakovsky et al. 2008; Katz et al. 2011; de Anna et al. 2014; Chagneau et al. 2015; Poonoosamy et al. 2016; Prasianakis et al. 2017), the processes in complex media, which are composed of many different mineral phases with a broad range of pore sizes, are still not well understood. 
Table 1 Outline of composite specimens.

\begin{tabular}{|c|c|c|c|c|c|c|}
\hline \multirow{2}{*}{ Specimen } & \multicolumn{2}{|c|}{ Cement paste } & \multicolumn{4}{|c|}{ Bentonite } \\
\hline & Type of cement & $\mathrm{W} / \mathrm{C}$ & Type of bentonite & Type of carbonate & Carbonate/ dried bentonite & Dry density \\
\hline $\mathrm{BL}$ & \multirow{3}{*}{$\begin{array}{c}\text { Ordinary } \\
\text { Portland } \\
\text { cement (OPC) }\end{array}$} & \multirow{3}{*}{0.60} & \multirow{3}{*}{$\begin{array}{c}\text { Na-type } \\
\text { (Kunigel V1) }\end{array}$} & - & 0 & \multirow{3}{*}{$1.6 \times 10^{3} \mathrm{~kg} / \mathrm{m}^{3}$} \\
\hline $\mathrm{NC1}$ & & & & $\mathrm{Na}_{2} \mathrm{CO}_{3}$ & $1.0 \%$ & \\
\hline $\mathrm{NC} 4$ & & & & $\mathrm{Na}_{2} \mathrm{CO}_{3}$ & $4.0 \%$ & \\
\hline
\end{tabular}

Table 2 Chemical compositions of cement and bentonite (wt\%).

\begin{tabular}{|c|c|c|c|c|c|c|c|c|c|c|c|c|c|c|c|}
\hline & $\mathrm{SiO}_{2}$ & $\mathrm{Al}_{2} \mathrm{O}_{3}$ & $\mathrm{Fe}_{2} \mathrm{O}_{3}$ & $\mathrm{CaO}$ & $\mathrm{MgO}$ & $\mathrm{SO}_{3}$ & $\mathrm{Na}_{2} \mathrm{O}$ & $\mathrm{K}_{2} \mathrm{O}$ & $\mathrm{TiO}_{2}$ & $\mathrm{P}_{2} \mathrm{O}_{3}$ & $\mathrm{MnO}$ & $\mathrm{Cl}$ & ig.loss & Insol. \\
\hline Cement & 21.28 & 5.09 & 3.15 & 65.36 & 1.01 & 2.01 & 0.32 & 0.41 & 0.25 & 0.14 & 0.10 & 0.006 & 0.84 & 0.10 \\
\hline Bentonite & 70.7 & 13.8 & 1.49 & 2.30 & 2.26 & 0.29 & 2.56 & 0.33 & 0.20 & 0.05 & 0.08 & $<0.001$ & 5.12 & - \\
\hline
\end{tabular}

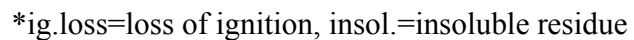

The main objectives of the present study are 1) to improve the fundamental understanding of calcite precipitation at cement-clay interfaces by accelerating the precipitation and 2) to investigate the possibility of complete clogging of interfacial porosity by the addition of carbonate to a bentonite mixture. Such experimental data improve system understanding and allow validation of computer simulations for the long-term evolution of cement-clay interfaces. In this first study, we conducted experiments using cement-bentonite composite specimens immersed in water in a laboratory. We investigated the effect of adding sodium carbonate to pure bentonite by immersion tests in order to enforce calcite precipitation. After 4, 10, and 20 months, the degradation of the cement paste and bentonite was investigated postmortem using several experimental techniques to determine the progress of mineral alteration fronts and changes in porosity. Acceleration of ionic migration using electromigration methods is discussed in the second paper (Nakarai et al. 2021).

\section{Material and methods}

The experimental setup follows the experimental protocol for cement-clay interaction prescribed by the Radioactive Waste Management Funding and Research Center (RWMC 2008) in Japan. The RWMC investigated the evolution of cement-bentonite samples in immersion tests and reported the results of immersion tests for 10 and 20 months (RWMC 2010, 2011). In this study, we investigated the effect of adding varying amounts of sodium carbonate to bentonite (see Table 1). A reference sample without carbonate (samples BL), identical to the previous investigations, was also prepared.

\subsection{Composite specimen consisting of ben- tonite and cement paste}

For the immersion tests, composite specimens consisting of cement paste and bentonite materials were prepared. Table 1 summarizes the material properties and the mixing ratio of sodium carbonate admixtures to the weight of dried bentonite (\%) and Fig. 1 shows the experimental configuration and sample dimensions. As alteration for the limited immersion test periods should be observed only in the surface layers at the interface (Jenni et al. 2014; Luraschi et al. 2020), the small specimens were prepared.

The cement used in this experiment was ordinary Portland cement (OPC) without any admixtures and was specifically supplied by the Japan Cement Association (JCA) for research purposes. The chemical composition of the cement, based on the Japanese standard JIS R 5202 (2005), is listed in Table 2.

The high water-to-cement ratio of 0.60 for producing the cement paste samples resulted in high porosity, large pores (Cook and Hover 1999) and high diffusivity and

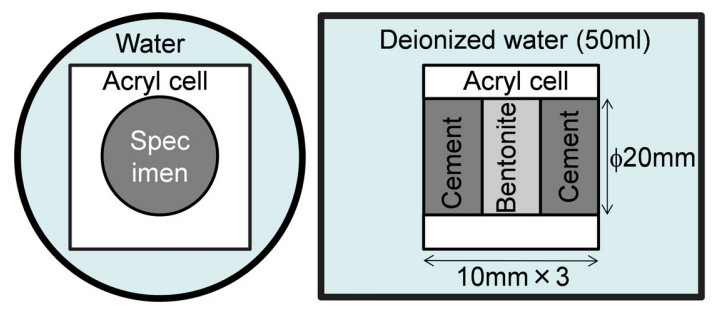

(a) Immersion test for detailed analysis (full model).

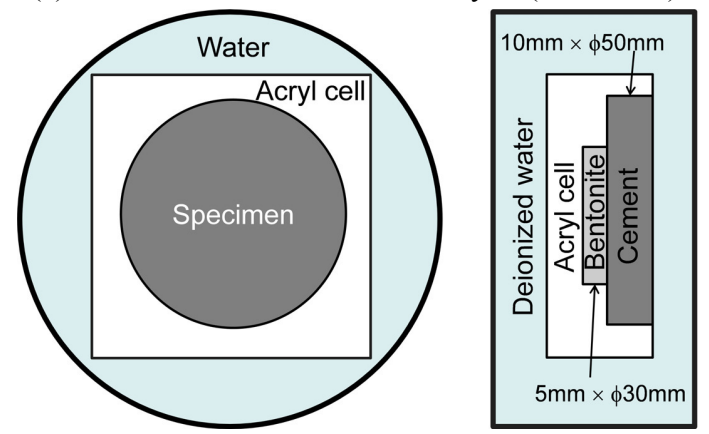

(b) Immersion test for the chloride migration test (half model).
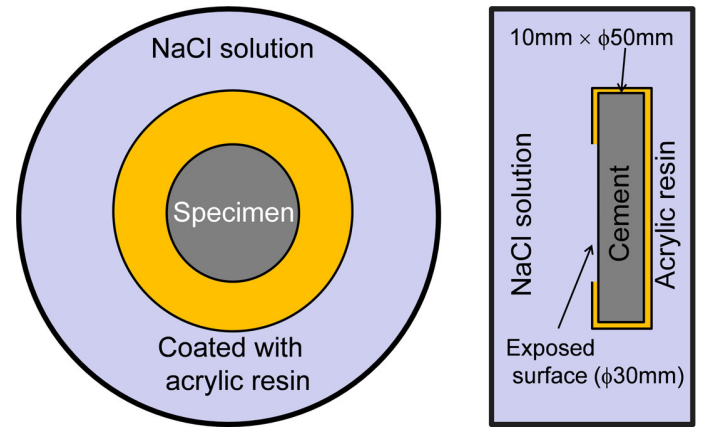

(c) Chloride migration tests.

Fig. 1 Schematic diagrams of the cells for investigating the cement-bentonite interaction (left: cross section view, right: longitudinal cross section view). 
decreased the degradation resistance of the cement paste (Bentz and Garboczi 1992). Cement and water were mechanically mixed at $30^{\circ} \mathrm{C}$. Before casting, the cement paste was allowed to rest in a bag for several hours at 30 ${ }^{\circ} \mathrm{C}$ : in the first $2-3 \mathrm{~h}$, the cement paste was mixed every hour, and then mixing was done every 30 minutes until bleeding from the segregation disappeared. After casting, cylindrical specimens $(\phi 20 \mathrm{~mm} \times 70 \mathrm{~mm})$ of cement paste were cured in hot water at $50{ }^{\circ} \mathrm{C}$ for 28 days to ensure mature cement hydration. After curing, the specimens were cut in $10 \mathrm{~mm}$ thick disks for the immersion tests. The chemical composition of the cement used is shown in Table 2.

The bentonite used in this study was Kunigel-V1, a Japanese sodium-type bentonite. The chemical composition of Kunigel-V1, as reported in the literature (Ito et al. 1993), is summarized in Table 2. In terms of mineralogy the bentonite included montmorillonite (47 wt $\%$ ), quartz $(37.5 \mathrm{wt} \%)$, plagioclase $(4.1 \mathrm{wt} \%)$, analcime $(3.3$ $\mathrm{wt} \%)$, calcite $(2.4 \mathrm{wt} \%)$, dolomite $(2.0 \mathrm{wt} \%)$, and pyrite (0.6 wt\%) (Ito et al. 1993).

Three types of bentonite samples were prepared: pure bentonite (BL) and bentonite samples mixed with $1 \%$ and $4 \%$ sodium carbonate $\left(\mathrm{Na}_{2} \mathrm{CO}_{3}\right)(\mathrm{NCl}$ and $\mathrm{NC} 4$, respectively) relative to the dried bentonite weight. The addition of carbonate in such amounts can provide sufficient carbonate to allow for pore clogging near the interface in a short time. In the case of carbonate-bentonite samples ( $\mathrm{NC1}$ and $\mathrm{NC4}$ ), powdered chemicals were used for preparing mixtures. The mixtures were prepared such that the bentonite and sodium carbonate were homogeneously mixed. Then, the bentonite mixtures were statically compacted using a compressive machine. The dry density of the bentonite samples was found to be $1.6 \times 10^{3} \mathrm{~kg} / \mathrm{m}^{3}$, which is around the designed value for the radioactive repository (Masuda et al. 1999).

For the immersion test, composite specimens with bentonite samples between two cement paste samples were prepared by Taiheiyo Consultant Co. Ltd. (Fig. 1(a)). First, a shaped cement paste sample was placed on one side of the acrylic resin cells with an inner diameter of $20 \mathrm{~mm}$ and length of $30 \mathrm{~mm}$. Then, the compacted bentonite sample was positioned on the cement paste, and finally, another cement paste sample was placed on the top of the cell.

Furthermore, chloride migration tests were conducted after the immersion tests at Hiroshima University. For these tests, additional specimens were prepared (Fig. 1(c)) after immersion (Fig. 1(b)) as half models of the above specimens (Fig. 1(a)). The half model consisted of a $5 \mathrm{~mm}$-thick bentonite disc that was set on top of a 10 mm-thick cement paste disc (Fig. 1(b)). The full model consisted of a $10 \mathrm{~mm}$-thick bentonite disc sandwiched between two $10 \mathrm{~mm}$-thick discs of cement paste (Fig. 1(a)). The different diameters of discs were necessary because of size limitations associated with some experimental equipment.

\subsection{Immersion tests of the composite specimen}

Before the actual immersion, the composite specimens were vacuum-saturated with deionized water. This leaches the alkalis in the initial cement pore solution and transforms the cement from the initial "Stage I" state (Berner 1992), which is characterized by high alkali concentrations and a $\mathrm{pH}$ of $>13$, into a "Stage II" state (Berner 1992), where the $\mathrm{pH}$ is buffered at $\sim 12.5$ by the existence of portlandite. During the pre-saturation procedure, the saturation of bentonite without cracking was visually checked from homogenous color changes of the specimens. Finally, the composite specimen was placed in $50 \mathrm{~mL}$ of deionized water for the immersion tests (see Fig. 1), which gave a liquid-to-solid ratio of approximately 5.3 by volume. The measured $\mathrm{pH}$ after 10 months of immersion test was 12.70 (RWMC 2010).

For bentonite, negatively charged species can only enter part of the pore space; they are repelled from negatively charged clay surfaces and cannot enter mono- or bi-hydrated clay interlayers (Van Loon et al. 2007). The fraction of the so-called anion accessible porosity depends on the type of bentonite, its compaction, and the ionic strength of the solution. For high compaction, the fraction of anion accessible porosity might become very small, as most water is present in the interlayers. In this study, Kunigel-V1 was compacted to a dry density of $1.6 \times 10^{3} \mathrm{~kg} / \mathrm{m}^{3}$. For this density, the total porosity can be approximated to be 0.4 and the anionic porosity value to be 0.08 ( 0.2 of the total porosity) (Ishidera et al. 2008). If negatively charged carbonate complexes are excluded from the interlayer water of montmorillonite after re-saturation, the added sodium carbonate for the $4 \%$ mixture exceeds its solubility limit $(30.7 \mathrm{~g} / 100 \mathrm{~g}$ water at $25^{\circ} \mathrm{C}$ ) for the (anion) accessible porosity. For the samples with $1 \%$ carbonate addition, the sodium carbonate is completely dissolved.

\subsection{Chloride migration tests of the cement paste specimen}

After 4 months of immersion tests for the half-models shown in Fig. 1(b), the cement paste samples were carefully prepared for the chloride migration tests as illustrated in Fig. 1(c). All surfaces, except the interface with bentonite in the former immersion tests, were coated with acryloyl-modified acrylic resin. This allows one-dimensional in-diffusion tests with $\mathrm{NaCl}$ solution (3\% in mass) for $48 \mathrm{~h}$ from the surface affected by the contacted bentonite.

\subsection{Experimental methods}

After 4, 10, and 20 months of the immersion tests, test cells for detailed analysis were selected (Fig. 1(a)). The specimens were dismantled and cut into smaller samples using a diamond saw, as illustrated in Fig. 2(a). The sub-samples were analyzed by electron probe micro-analysis (EPMA), thermogravimetry/differential thermal analysis (TG-DTA), and X-ray diffraction (XRD). In addition, for TG-DTA and XRD measure- 
ments, powder samples of the interface surface layers with $1 \mathrm{~mm}$ thickness for the cement paste and $2 \mathrm{~mm}$ thickness for the bentonite were prepared. The sample thickness was chosen based on the thickness of the alteration zone measured by EPMA.

After completing the chloride migration tests, the specific specimens were also cut into smaller samples, as shown in Fig. 2(b). EPMA measurements were conducted on the cross section indicated in Fig. 2(b) to qualitatively investigate chloride migration.

Each measurement was conducted using one sample from the specimens, although it was not sufficient to capture the variability among samples. As significant inconsistency among the results (e.g. unbalanced alteration between two cement-bentonite interfaces, unstable progress of degradation with time) for each sample was not observed, the experiments are well suited to capture the basic processes responsible for porosity change at the interface and to improve understanding on the effect of adding carbonate to the bentonite.

\section{(1) EPMA measurement}

Chemical element mapping on cross sections of the composite specimens was conducted using a JXA-8200 (JEOL Ltd., Japan) electron probe microanalyzer. The polished plain surface was coated with carbon $(25-30 \mathrm{~nm}$ thick) as the conductive material. The acceleration voltage was $15 \mathrm{kV}$ and the pixel size was $40 \mu \mathrm{m} \times 40 \mu \mathrm{m}$, with a counting interval of $40 \mathrm{~ms}$. A standard published by JSCE (JSCE 2005) has been referred.

\section{(2) XRD analysis}

Mineral contents on the surface layer of the cement paste were qualitatively analyzed by XRD using an X'Pert
PRO (PANalytical, Netherlands) diffractometer. The measurement conditions were as follows: X-ray source $\mathrm{Cu}-\mathrm{K} \alpha$, tube voltage $40 \mathrm{kV}$, tube current $45 \mathrm{~mA}$, scanning range $2 \theta=5^{\circ}$ to $60^{\circ}$, step width $0.017^{\circ}$, and a measurement time for one step of $0.2 \mathrm{~s}$.

\section{(3) Thermal analysis}

Samples from the surface layer of the cement paste and the surface and inner layers were prepared for TG-DTA using a Thermo plus evo2 TG8121 (Rigaku, Japan). The change in weight was measured from room temperature to $1000{ }^{\circ} \mathrm{C}$ with the temperature ramped up at a rate of 10 ${ }^{\circ} \mathrm{C} / \mathrm{min}$ under nitrogen gas flow. The temperature ranges for calculating the amounts of calcium hydroxide $\left(\mathrm{Ca}(\mathrm{OH})_{2}\right)$ and calcium carbonate $\left(\mathrm{CaCO}_{3}\right)$ were determined from the measured DTA curves. The determined ranges were approximately $410-470{ }^{\circ} \mathrm{C}$ for $\mathrm{Ca}(\mathrm{OH})_{2}$ and $510-710^{\circ} \mathrm{C}$ for $\mathrm{CaCO}_{3}$.

\section{Experimental results and discussion}

The results of calcium elemental mapping on cross sections of the composite specimens after 20 months of immersion are shown in Fig. 3. Some cracks are visible in both the cement paste and bentonite. These artifacts are probably caused by drying as a necessary part of the sample preparation process, because there were no mineralogical alternations observed in or around the cracks. In the cement paste adjacent to the interfaces, a decrease in the calcium content is observed. The extension of the calcium-depleted zone is inversely correlated to the amount of premixed carbonate in the bentonite. For a sample with a high premixed carbonate content, the width of the calcium-depleted surface layer is smaller.

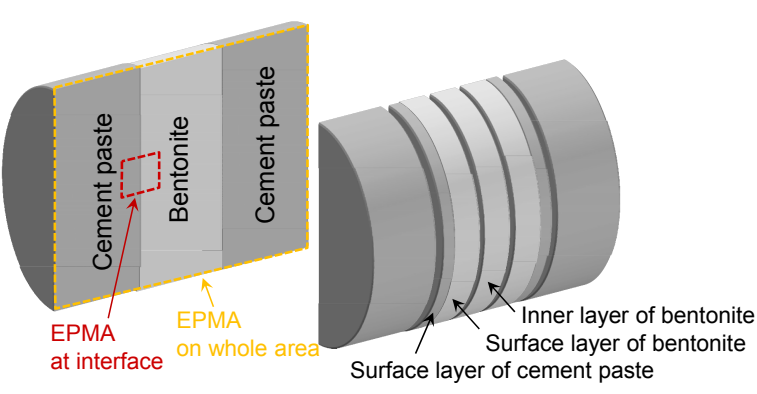

(a) Samples for measurement after immersion tests

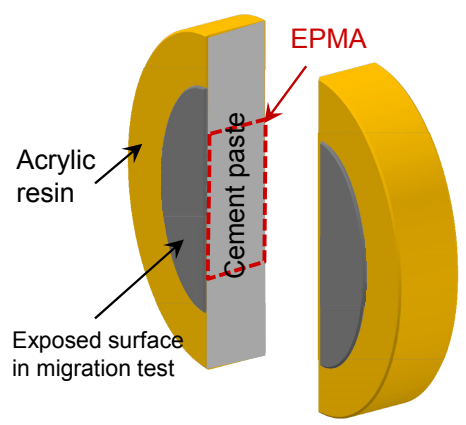

(b) Samples for measurement after chloride migration tests Fig. 2 Sample treatments for measurement.
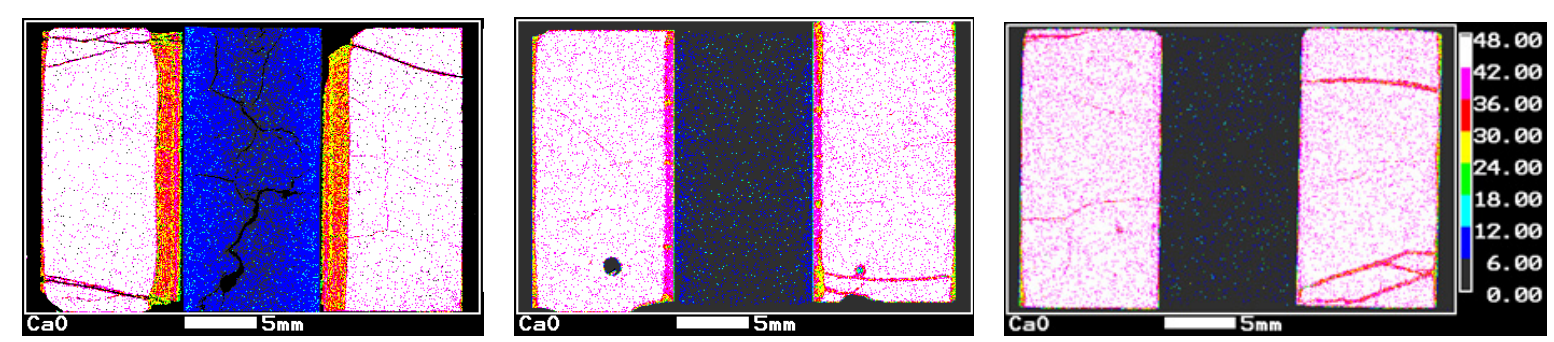

Fig. 3 Calcium element mapping (wt\%) measured by EPMA on the specimens (cement paste-bentonite-cement paste) after 20 months. (Left: BL-20M; Center: NC1-20M; Right: NC4-20M). 
This observation will be discussed later in the paper considering pore clogging.

For a detailed quantitative analysis, longitudinal profiles for selected elements across the alteration zones at the interfaces were constructed from the EPMA measurements (Fig. 4). The profiles for the initial element contents in the cement paste and bentonite were interpolated from unaltered material compositions after 4 months of interaction (dashed lines in Fig. 4). The profiles of aluminum, magnesium, and iron show fewer changes and the detailed measurements are included in the Appendix.

The results of XRD (Fig. 5 and Appendix) and TG-DTA (Fig. 6) on the cement side show an increase in portlandite and calcite in the surface layers of cement paste specimens as the amount of carbonate admixture is increased. For sample BL (no carbonate admixture), the portlandite was completely dissolved and no calcite was present after 20 months, while for sample NC4 (4\% carbonate admixture), both portlandite and calcite are present.

Figure 7 shows the measured XRD patterns from the bentonite surface layer within the range between $26^{\circ}$ and $31^{\circ}$ for the initial and final specimens in this study. The XRD patterns for all specimens are given in the Appendix. Samples BL and $\mathrm{NC1}$ showed evidence of smectite dissolution after 20 months, while C-S-H seems to have precipitated. Sample NC4 shows no significant change that can be related to the change in mineralogy.

\subsection{Minerological evolution at interface of ref- erence sample without carbonate admixture}

In the case of BL, high and continuous diffusion across the interface caused strong changes not only in calcium but also in sodium, silica, and sulfate. Calcium leaching
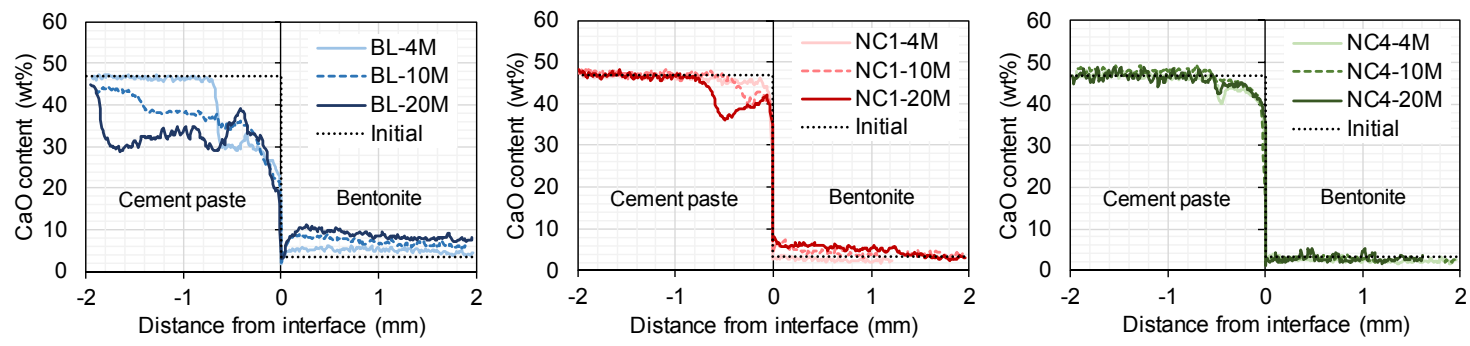

(a) Distribution of calcium at the cement-bentonite interface.
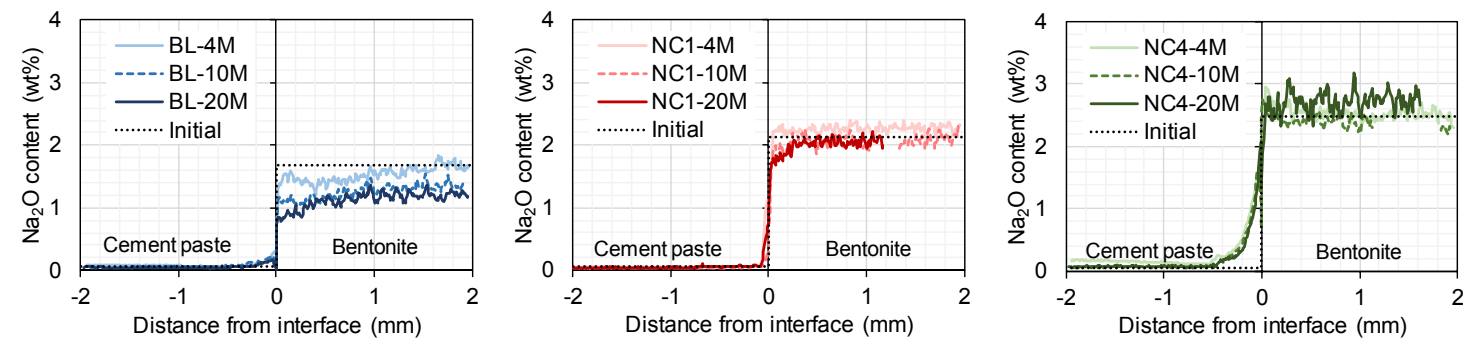

(b) Distribution of sodium at the cement-bentonite interface.
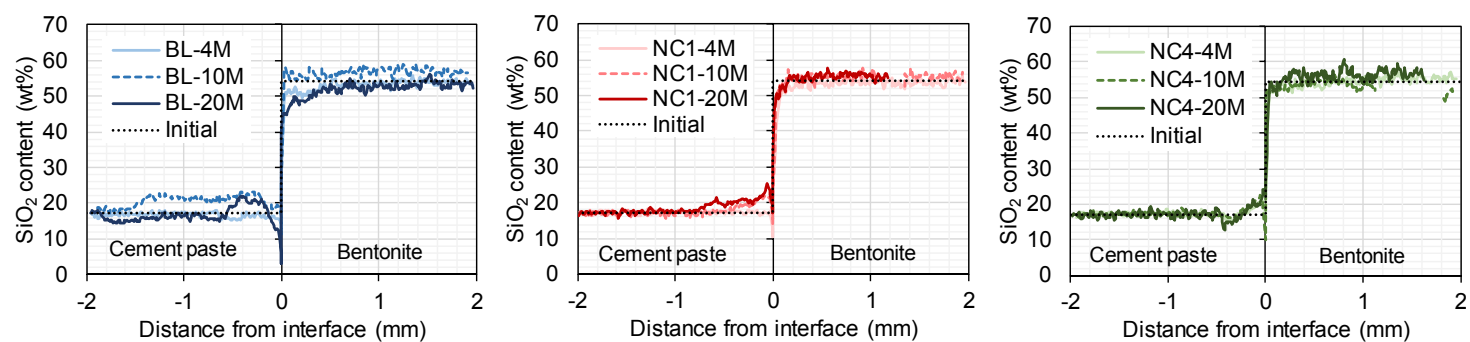

(c) Distribution of silicon at the cement-bentonite interface.
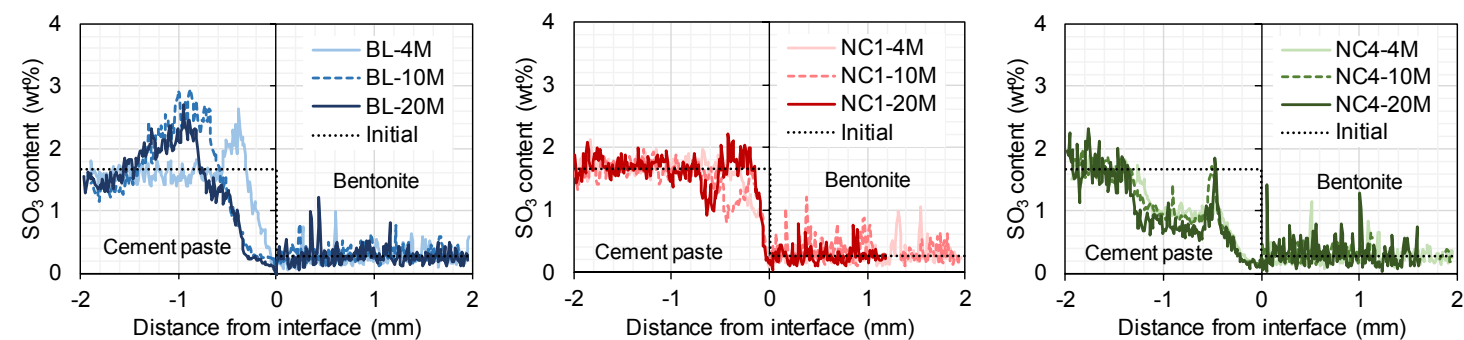

(d) Distribution of sulfate at the cement-bentonite interface.

Fig. 4 Longitudinal profiles of main chemical compositions measured by EPMA. 
decreased the calcium content in the cement side and increased the calcium in the bentonite side (Fig. 4(a)). Calcium leaching causes portlandite to quickly disappear at the surface of the cement paste (Figs. 5 and 6). The degraded depth of cement paste with time, defined by the calcium-leached depth from the interface in Fig. 4(a), is plotted in Fig. 8. The calcium-leached depth was obtained from the area showing clear drop of calcium concentration measured by EPMA. The depth of the calcium-depleted zone increased in proportion to the square root of time, similar to other immersion tests of cement paste in solutions (Carde et al. 1997; Haga et al. 2005; Choi and Yang 2013). Square-root dependency is typically found in processes that are controlled by diffusive transport, for example, for reaction fronts originating from cement/clay interaction (Kosakowski and Berner 2013; Kosakowski et al. 2014) and for the progress of carbonation fronts (Papadakis et al. 1989; Richardson 2002; Ta et al. 2016).

In addition, in the calcium-leached area of the cement paste, sulfur content was depleted and sulfur accumulated at the leaching front (Fig. 4). This observation can be explained by the release of sulfate from ettringite/monosulfate decalcification and re-precipitation at the leaching front because of high $\mathrm{pH}$, similar to what is observed during carbonation (Kobayashi et al. 1990).

In the bentonite, the calcium increase corresponded to

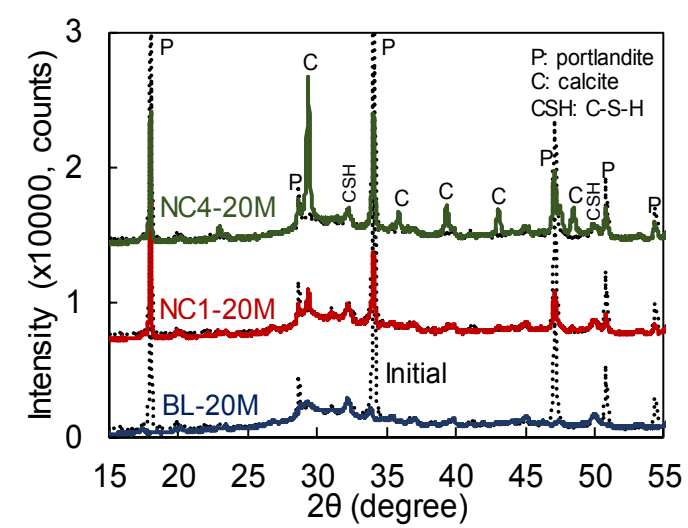

Fig. 5 Changes in XRD intensities of minerals at the surface layer of cement paste specimens before and after immersion tests (dated lines show results before, and solid lines show results after the tests).

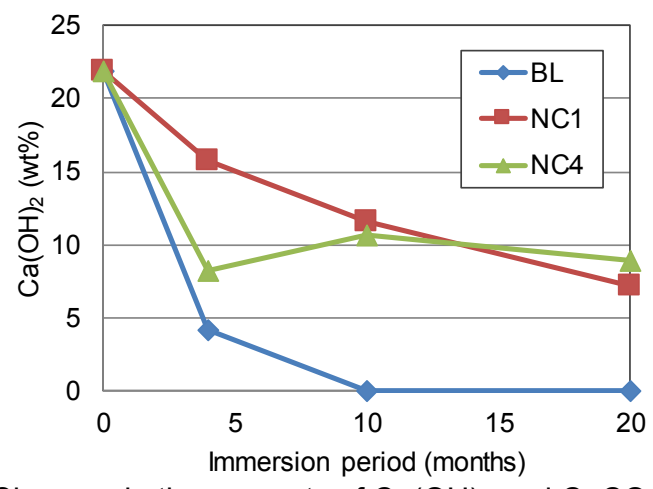

Fig. 6 Changes in the amounts of $\mathrm{Ca}(\mathrm{OH})_{2}$ and $\mathrm{CaCO}_{3}$ measured by TG-DTA at the surface layer of cement paste the decrease in sodium content, which suggests cation exchange (Sposito et al. 1983). Furthermore, silica dissolution at the surface layer of bentonite was observed (Fig. 4). The dissolution of quartz and clay minerals is known to be accelerated at high $\mathrm{pH}$ (Palandri and Kharaka 2004).

The XRD measurements from the bentonite surface layer (Fig. 7) suggest that the dissolution of smectite in bentonite is caused by the high $\mathrm{pH}$ front progressing into bentonite from the cement side. The increase in $\mathrm{pH}$ in bentonite is supported by the formation of $\mathrm{C}-\mathrm{S}-\mathrm{H}$ detected on the clay surface. This observation is consistent with other experimental studies (Dauzeres et al. 2010; Fernández et al. 2016) and numerical modeling (De Windt et al. 2004; Kosakowski and Berner 2013).

\subsection{Minerological evolution at interface of sam- ples with carbonate admixture}

\section{(1) Changes in cement paste}

The addition of sodium carbonate to bentonite altered the mineral evolution of the cement samples. The extent of calcium depletion and other changes in Figs. 4-6 and 8 was significantly smaller for samples with additional sodium carbonate.

With the addition of $1 \%$ sodium carbonate $(\mathrm{NC} 1)$, the

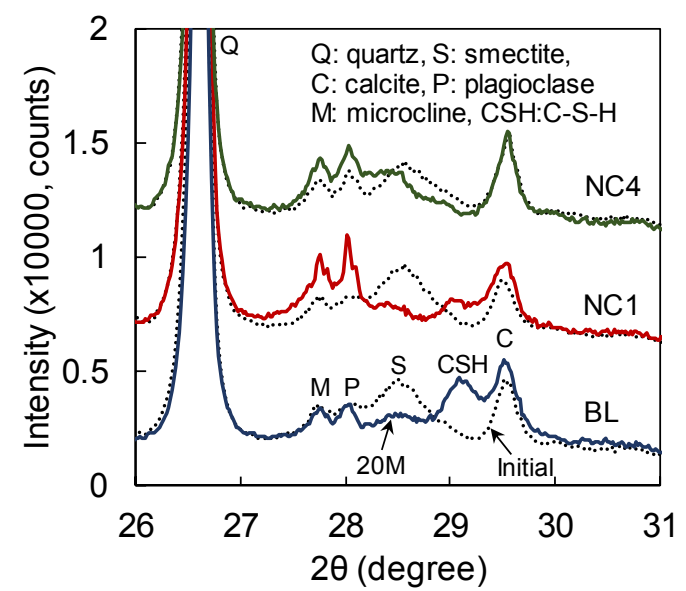

Fig. 7 Changes in XRD intensities of minerals at the surface layer of bentonite specimens before and after immersion tests (dated lines show results before, and solid lines show results after the tests).

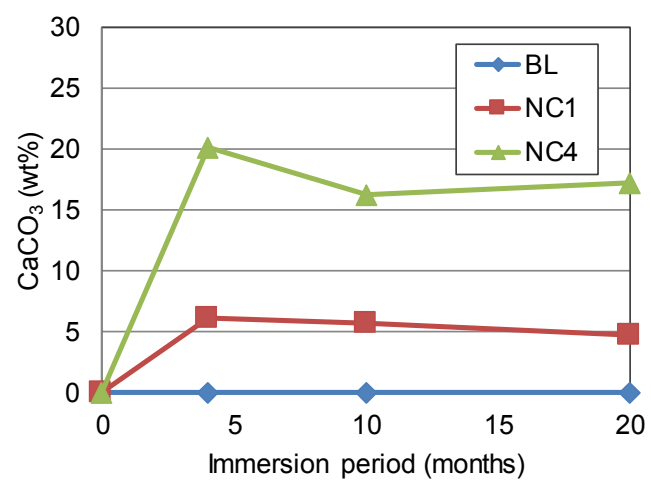


decrease in the calcium concentration on the cement paste and its increase in on the bentonite were much smaller than those without carbonate (Fig. 4(a)). These observations indicate reduced diffusive fluxes across the interface owing to partial pore clogging caused by calcite precipitation at the interface. However, the progress of calcium leaching from cement paste was not stopped and was also proportional to the square root of time after 4 months (Fig. 8). The XRD (Fig. 5 and Appendix) and TG-DTA (Fig. 6) results show that mineral changes at the surface of cement paste in the cases with sodium carbonate added to bentonite depended on the amount of carbonate added. For samples NC1 (less carbonate mixing), portlandite continuously dissolves with rates decreasing proportionally to the square root of time (Fig. 6). Calcite precipitation occurred within less than 4 months and no significant changes were observed later.

In samples with $4 \%$ sodium carbonate addition ( $\mathrm{NC} 4$ ), the degraded depth did not change after 4 months, as shown in Figs. $\mathbf{4}$ and $\mathbf{8}$. Relatively large changes at the interface were observed in the first measurements (4 months). The distinctive changes were the increase in sodium content and the decrease in sulfate content in the surface layer of the cement paste (Fig. 4), and more than half of the portlandite dissolved quickly (Figs. 5 and 6). Large amounts of calcite were precipitated for $\mathrm{NC4}$ during the first 4 months. The amount of calcium necessary for calcite precipitation was close to the amount of calcium released by portlandite dissolution; this strongly indicated the proposed carbonation reaction. Although secondary mineral precipitations such as feldspar after ettringite/monosulfate dissolution seem possible by the increases in sodium and silicon, XRD patterns did not detect any additional minerals except calcite (Fig. 5).

\section{(2) Changes in bentonite}

In the initial samples, there were no significant differences visible for samples with and without an admixture of sodium carbonate. After immersion tests for 20 months, mineralogical alterations were clearly observed in $\mathrm{BL}$ and $\mathrm{NC} 1$, while NC4 did not show any significant changes (Fig. 7 and Appendix). In the case of BL, the smectite peak disappeared and $\mathrm{C}-\mathrm{S}-\mathrm{H}$ was detected. In

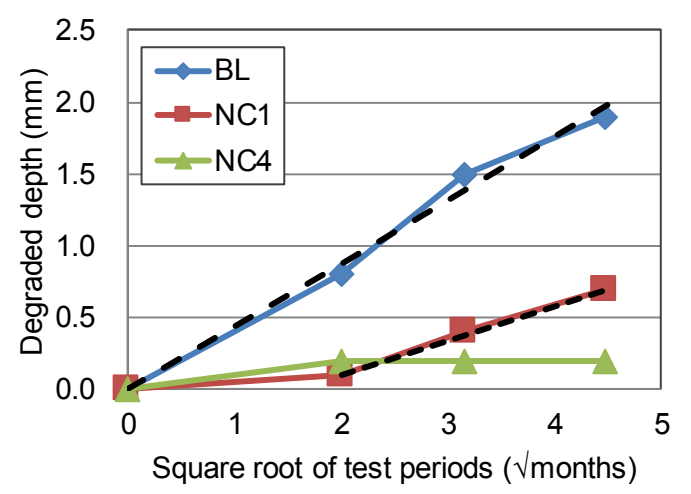

Fig. 8 Depth of degradation cause by calcium leaching from the interface in cement paste. the case of $\mathrm{NC} 1$, the smectite peak also disappeared and the peaks at $\sim 28.5^{\circ}$ were shifted to lower angles related to zeolite or feldspar. These observations indicate the dissolution of smectite in bentonite and the precipitation of secondary minerals associated with calcium leaching from cement paste. During sample collection after the immersion tests, hardened bentonite mixtures were observed in BL and NC1. This implied a change in the structure of bentonite by cementation with secondary mineral precipitation.

\section{(3) Effect of amount of carbonate mixture}

Maximum potential amounts of calcite precipitation in the surface layer of the cement paste specimen were calculated (Fig. 9). We assumed that all premixed carbonate in bentonite was consumed to generate $\mathrm{CaCO}_{3}$ in this 1-mm layer during immersion tests. The calcite contents of the original bentonite were not considered because calcite precipitation in the cement paste of BL and changes in the calcite peak in bentonite mixtures were not observed by TG-DTA and XRD.

The relationship between the amount of calculated potential and measured $\mathrm{CaCO}_{3}$ is plotted in Fig. 9. For $\mathrm{NC} 1$ (low carbonate admixture), the measured $\mathrm{CaCO}_{3}$ almost agrees with the calculated potential amount. This indicates that the admixed carbonate was completely used to precipitate $\mathrm{CaCO}_{3}$ in the surface layer of the cement paste. For the NC4 case (high carbonate admixture), the measured amount was much smaller than the calculated potential amount. This and the existence of portlandite after 4 months implies that only part of the carbonate was used to form calcite. In combination with the observation that the evolution of the system stopped completely after 4 months, it can be assumed that the calcite precipitation in case NC4 clogged the pore space and prevented the migration of remaining carbonate into the cement sample. Furthermore, the measured amount of $20 \%$ calcite can be interpreted as a threshold value necessary to clog the pore space. The amount necessary to clog the pore space is specific for this cement, as porosity (pore size distribution) and composition in terms of hydrated cement minerals influence the amount of

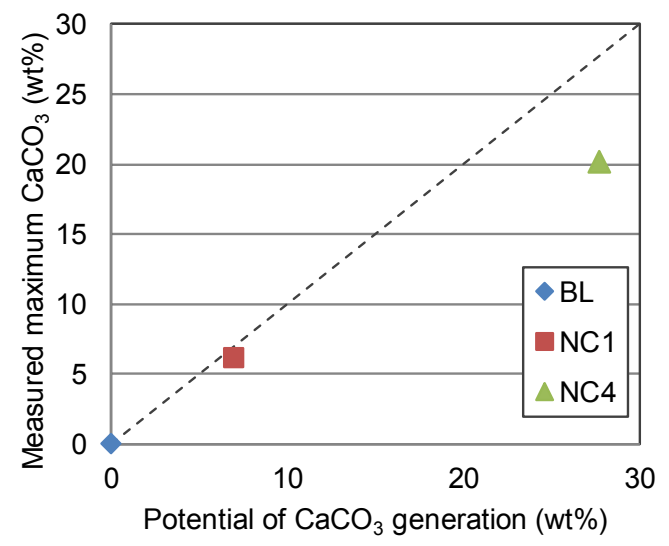

Fig. 9 Relationship between potential and measured amounts of $\mathrm{CaCO}_{3}$. 
calcite needed to fill the pore space.

\subsection{Post transport properties of cement paste contacted with bentonite}

The hypothesis of pore clogging is supported by the results of chloride migration tests. The diffusive flux across the interface for the different samples can be demonstrated with the help of the chloride profiles shown in Fig. 10. Chloride diffusion across the interfaces (exposed surface) was clearly observed in the BL and $\mathrm{NC} 1$ cases. A similar extension of chloride penetration depth for $\mathrm{BL}$ and $\mathrm{NC} 1$ indicates that transport across the interface is similar, although the mineralogical evolution of the interface is not identical. This is in line with the observation of the continuous progress of calcium leaching shown in Fig. 8. For sample NC4, considerably less chloride crossed the surface. The significant reduction in mass flux can therefore support the hypothesis of pore clogging by rapid calcite precipitation. This also agrees with the constant degraded depth after 4 months observed in Figs. 4 and 8. The effect of heterogeneity of the microstructure should be discussed using long-term experimental results in the future.

\section{Conclusions}

In this study, the cement-bentonite interface reaction with a focus on calcite precipitation was investigated on composite specimens of cement paste and compressed bentonite/carbonate mixtures. To accelerate the calcite precipitation at the interface, sodium carbonate was premixed into the bentonite.

Our experimental results revealed that premixed carbonate in bentonite indeed promotes calcite precipitation in the surface layer of the cement paste in contact with bentonite if the initial amount of premixed carbonate is sufficiently high. When the carbonate content was too low, alteration still progressed at a slower rate after calcite precipitation and the transport property of the cement paste did not change. Conversely, a sufficiently high carbonate content resulted in less alteration, a stable composition, and significant reduction of post chloride migration after the early reaction. This suggests pore clogging at the interface, thus implying the existence of a threshold amount of carbonate for pore clogging.

The first samples taken after 4 months already sug- gested a completely clogged interface for high carbonate admixture samples. Therefore, our measurements did not provide detailed insight into how fast calcite precipitation and pore clogging occurred. We suspect that the clogging had to occur very quickly, as alterations near the interface were very small.

Owing to the small number of samples, the influence of material heterogeneity on interface evolution and clogging conditions could not be determined in this study. However, the analysis shows consistency in terms of mass balance and allows the research to clearly quantify the effect of carbonate addition to bentonite, such that our results can be considered representative in terms of interface evolution and processes that drive porosity clogging.

To determine the feasibility of premixed carbonate to engineered barrier systems for surface and deep geological disposal of radioactive waste, field studies are needed that investigate the properties and the long-term stability of such clogged interfaces under the influence of changes in mechanical loading, thermal pulse or chemical gradients. As pore structure of cementitious materials is one of the key factors controlling pore clogging, microstructure analysis using scanning electron microscopy (SEM), atomic force microscope (AFM), X-ray and neutron tomography, and other methods should also be conducted in future studies. Selective application of the premixed carbonate should be additionally discussed as an effective method for thick bentonite barriers.

\section{Acknowledgements}

Assistance with the chloride migration tests was provided by Assistant Professor Yuko Ogawa and a former student, Mr. Kensuke Kozuka, from Hiroshima University.

This work was supported by the Japan Society for the Promotion of Science, JSPS KAKENHI [Grant numbers JP20686029, JP15KK0239]. The immersion test results without carbonates in RWMC reports were obtained from "Development of long-term performance assessment method for engineered barrier of TRU radioactive waste repository (FY2007, FY2009 and FY2010)" under a grant from the Agency for Natural Resources and Energy (ANRE) in the Ministry of Economy, Trade and Industry (METI) of Japan. The measurements of immersion tests with carbonates were supported by the
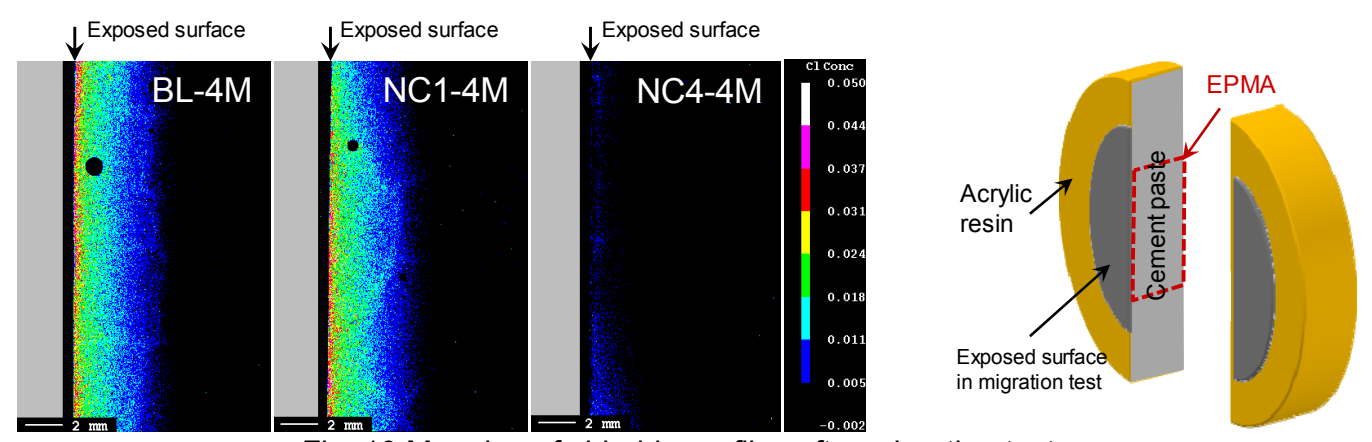

Fig. 10 Mapping of chloride profiles after migration tests. 
Nuclear Safety Research Association (NSRA) in the framework of "Investigation of technical issues for understanding the long-term behavior of engineered barrier systems (Phase II)" performed by NSRA, Taiheiyo Consultant Corp., and Hazama Ando Corp. under contract with the Nuclear Waste Management Organization of Japan (NUMO).

\section{References}

Al-Salloum, Y., Hadi, S., Abbas, H., Almusallam, T. and Moslem, M. A., (2017). "Bio-induction and bioremediation of cementitious composites using microbial mineral precipitation - A review." Construction and Building Materials, 154, 857-876.

Alexander, W. R. and McKinley, L., (2007). "Deep geological disposal of radioactive waste." Elsevier.

Balmer, S., Kaufhold, S. and Dohrmann, R., (2017). "Cement-bentonite-iron interactions on small scale tests for testing performance of bentonites as a barrier in high-level radioactive waste repository concepts." Applied Clay Science, 135, 427-436.

Bentz, D. P. and Garboczi, E. J., (1992). "Modelling the leaching of calcium hydroxide from cement paste: effects on pore space percolation and diffusivity." Materials and Structures, 25(9), 523-533.

Berner, U., Kulik, D. A. and Kosakowski, G., (2013). "Geochemical impact of a low-pH cement liner on the near field of a repository for spent fuel and high-level radioactive waste." Physics and Chemistry of the Earth, 64, 46-56.

Berner, U. R., (1992). "Evolution of pore water chemistry during degradation of cement in a radioactive waste repository environment." Waste Management, 12(2), 201-219.

Blanc, P., Vieillard, P., Gailhanou, H., Gaboreau, S., Marty, N., Claret, F., Made, B. and Giffaut, E., (2015). "ThermoChimie database developments in the framework of cement/clay interactions." Applied Geochemistry, 55, 95-107.

Bronick, C. J. and Lal, R., (2005). "Soil structure and management: a review." Geoderma, 124(1-2), 3-22.

Buil, M., Revertegat, E. and Oliver, J., (1992). "A model of the attack of pure water or undersaturated lime solutions on cement." In: T. Gilliam and C. Wiles ed., Stabilization and Solidification of Hazardous, Radioactive, and Mixed Wastes: 2nd Volume, West Conshocken, PA: ASTM International, 227-241.

Carde, C., Escadeillas, G. and François, A. H., (1997). "Use of ammonium nitrate solution to simulate and accelerate the leaching of cement pastes due to deionized water." Magazine of Concrete Research, 49(181), 295-301.

Chagneau, A., Claret, F., Enzmann, F., Kersten, M., Heck, S., Made, B. and Schafer, T., (2015). "Mineral precipitation-induced porosity reduction and its effect on transport parameters in diffusion-controlled porous media." Geochemical Transactions, 16. 13.

Choi, Y. S. and Yang, E. I., (2013). "Effect of calcium leaching on the pore structure, strength, and chloride penetration resistance in concrete specimens." Nuclear Engineering and Design, 259, 126-136.

Cook, R. A. and Hover, K. C., (1999). "Mercury porosimetry of hardened cement pastes." Cement and Concrete Research, 29(6), 933-943.

Dauzeres, A., Le Bescop, P., Sardini, P. and Cau Dit Coumes, C., (2010). "Physico-chemical investigation of clayey/cement-based materials interaction in the context of geological waste disposal: Experimental approach and results." Cement and Concrete Research, 40(8), 1327-1340.

de Anna, P., Dentz, M., Tartakovsky, A. and Le Borgne, T., (2014). "The filamentary structure of mixing fronts and its control on reaction kinetics in porous media flows." Geophysical Research Letters, 41(13), 4586-4593.

DeJong, J. T., Mortensen, B. M., Martinez, B. C. and Nelson, D. C., (2010). "Bio-mediated soil improvement." Ecological engineering, 36(2), 197-210.

De Muynck, W., De Belie, N. and Verstraete, W., (2010). "Microbial carbonate precipitation in construction materials: A review." Ecological engineering, 36(2), 118-136.

De Windt, L., Pellegrini, D. and van der Lee, J., (2004). "Coupled modeling of cement/claystone interactions and radionuclide migration." Journal of Contaminant Hydrology, 68(3-4), 165-182.

Fernández, R., Ruiz, I. and Cuevas, J., (2016). "Formation of CASH phases from the interaction between concrete or cement and bentonite." Clay Minerals, 51(2), 223-235.

Fernández, R., Torres, E., Ruiz, A. I., Cuevas, J., Alonso, M. C., García Calvo, J. L., Rodríguez, E. and Turrero, M. J., (2017). "Interaction processes at the concrete-bentonite interface after 13 years of FEBEX-Plug operation. Part II: Bentonite contact." Physics and Chemistry of the Earth, Parts $A / B / C, 99$, 49-63.

Gaboreau, S., Lerouge, C., Dewonck, S., Linard, Y., Bourbon, X., Fialips, C., Mazurier, A., Prêt, D., Borschneck, D. and Montouillout, V., (2012). "In-situ interaction of cement paste and shotcrete with claystones in a deep disposal context." American Journal of Science, 312(3), 314-356.

Gaboreau, S., Prêt, D., Tinseau, E., Claret, F., Pellegrini, D. and Stammose, D., (2011). "15 years of in situ cement-argillite interaction from Tournemire URL: Characterisation of the multi-scale spatial heterogeneities of pore space evolution." Applied Geochemistry, 26(12), 2159-2171.

Gaboreau, S., Rodríguez-Cañas, E., Maeder, U., Jenni, A., Turrero, M. J. and Cuevas, J., (2020). "Concrete perturbation in a 13-year in situ concrete/bentonite interaction from FEBEX experiments. New insight of 2:1 Mg phyllosilicate precipitation at the interface." Applied Geochemistry, 118, 104624.

Gaucher, E. C. and Blanc, P., (2006). "Cement/clay 
interactions - A review: Experiments, natural analogues, and modeling." Waste Management, 26(7), 776-788.

Gaucher, E. C., Tournassat, C., Pearson, F. J., Blanc, P., Crouzet, C., Lerouge, C. and Altmann, S., (2009). "A robust model for pore-water chemistry of clayrock." Geochimica Et Cosmochimica Acta, 73(21), 6470-6487.

Glasser, F. and Atkins, M., (1994). "Cements in radioactive waste disposal." MRS Bulletin, 19(12), 33-38.

Gollapudi, U. K., Knutson, C. L., Bang, S. S. and Islam, M. R., (1995). "A new method for controlling leaching through permeable channels." Chemosphere, 30(4), 695-705.

Haga, K., Shibata, M., Hironaga, M., Tanaka, S. and Nagasaki, S., (2005). "Change in pore structure and composition of hardened cement paste during the process of dissolution." Cement and Concrete Research, 35(5), 943-950.

Hayek, M., Kosakowski, G. and Churakov, S., (2011). "Exact analytical solutions for a diffusion problem coupled with a precipitation - dissolution reaction and feedback of porosity change." Water Resources Research, 47(7).

Hayek, M., Kosakowski, G., Jakob, A. and Churakov, S. V., (2012). "A class of analytical solutions for multidimensional multispecies diffusive transport coupled with precipitation - dissolution reactions and porosity changes." Water Resources Research, 48(3).

Ho, L. S., Nakarai, K., Duc, M., Kouby, A. L., Maachi, A. and Sasaki, T., (2018). "Analysis of strength development in cement-treated soils under different curing conditions through microstructural and chemical investigations." Construction and Building Materials, 166, 634-646.

Huynh, N. N. T., Imamoto, K.-I. and Kiyohara, C., (2019). "A study on biomineralization using Bacillus Subtilis Natto for repeatability of self-healing concrete and strength improvement." Journal of Advanced Concrete Technology, 17(12), 700-714.

IAEA, (2011). "Disposal of radioactive waste (Specific safety requirements)." IAEA Safety Standards Series, No. SSR-5, Vienna: International Atomic Energy Agency.

Ishidera, T., Miyamotoy, S. and Sato, H., (2008). "Effect of sodium nitrate on the diffusion of $\mathrm{Cl}-$ and $\mathrm{I}-$ in compacted bentonite." Journal of Nuclear Science and Technology, 45(7), 610-616.

Ito, M., Okamoto, M., Shibata, M., Sasaki, Y., Danhara, T., Suzuki, K. and Watanabe, T., (1993). "Bentonite mineral composition analysis." Power Reactor and Nuclear Fuel Development Corporation.

Jenni, A., Mäder, U., Lerouge, C., Gaboreau, S. and Schwyn, B., (2014). "In situ interaction between different concretes and Opalinus Clay." Physics and Chemistry of the Earth, Parts $A / B / C, 70-71,71-83$.

JIS R 5202, (2005). "Methods for chemical analysis of cements." Tokyo: Japanese Standards Association.

JSCE, (2005). "Test method for chemical element distribution in concrete using EPMA (draft), (JSCE-G
574-2005)." Tokyo: Japan Society of Civil Engineering.

Katz, G. E., Berkowitz, B., Guadagnini, A. and Saaltink, M. W., (2011). "Experimental and modeling investigation of multicomponent reactive transport in porous media." Journal of Contaminant Hydrology, 120-21, 27-44.

Kobayashi, K., Shiraki, R. and Kawai, K., (1990). "Migration and concentration of chlorides, sulfides and alkali compounds in concrete caused by carbonation." Concrete Research and Technology, $1(2), 69-82$.

Kosakowski, G. and Berner, U., (2013). "The evolution of clay rock/cement interfaces in a cementitious repository for low- and intermediate level radioactive waste." Physics and Chemistry of the Earth, 64, 65-86.

Kosakowski, G., Berner, U., Wieland, E., Glaus, M. A. and Degueldre, C., (2014). "Geochemical evolution of the L/ILW near-field, (Naga Technical Report NTB 14-11)", Wettingen Switzerland: National Cooprative for the Disposal of Radioactive Waste.

Kosakowski, G. and Watanabe, N., (2014). "OpenGeoSys-Gem: A numerical tool for calculating geochemical and porosity changes in saturated and partially saturated media." Physics and Chemistry of the Earth, 70-71, 138-149.

Lang-Lenton León, J., (2001). "Radioactive waste management and sustainable development." NEA News, 18-20.

Liu, S., Jacques, D., Govaerts, J. and Wang, L., (2014). "Conceptual model analysis of interaction at a concrete-Boom Clay interface." Physics and Chemistry of the Earth, Parts $A / B / C, 70,150-159$.

Luraschi, P., Gimmi, T., Van Loon, L. R., Shafizadeh, A. and Churakov, S. V., (2020). "Evolution of HTO and $36 \mathrm{Cl}-$ diffusion through a reacting cement-clay interface (OPC paste-Na montmorillonite) over a time of six years." Applied Geochemistry, 104581.

Mäder, U., Jenni, A., Lerouge, C., Gaboreau, S., Miyoshi, S., Kimura, Y., Cloet, V., Fukaya, M., Claret, F., Otake, T., Shibata, M. and Lothenbach, B., (2017). "5-year chemico-physical evolution of concrete-claystone interfaces, Mont Terri rock laboratory (Switzerland)." Swiss Journal of Geosciences, 110, 307-327.

Masuda, S., Umeki, H, and Narito, M., (1999). "Technical reliability on geological disposal of HLW in Japan. Second progress report on research and development for the geological disposal of HLW in Japan." Nippon Genshiryoku Gakkai-Shi, 42(6), 486-506. (in Japanese)

Marty, N. C. M., Bildstein, O., Blanc, P., Claret, F., Cochepin, B., Gaucher, E. C., Jacques, D., Lartigue, J. E., Liu, S. H., Mayer, K. U., Meeussen, J. C. L., Munier, I., Pointeau, I., Su, D. Y. and Steefel, C. I., (2015). "Benchmarks for multicomponent reactive transport across a cement/clay interface." Computational Geosciences, 19(3), 635-653.

Marty, N. C. M., Tournassat, C., Burnol, A., Giffaut, E. 
and Gaucher, E. C., (2009). "Influence of reaction kinetics and mesh refinement on the numerical modelling of concrete/clay interactions." Journal of Hydrology, 364(1), 58-72.

Metcalfe, R. and Walker, C., (2004). "Proceedings of the International Workshop on Bentonite-Cement Interaction in Repository Environments, (NUMO-TR-04-05)." Tokyo: Nuclear Waste Management Organization of Japan (NUMO).

Nakarai, K., Ishida, T. and Maekawa, K., (2006a). "Modeling of calcium leaching from Cement hydrates coupled with micro-pore formation." Journal of Advanced Concrete Technology, 4(3), 395-407.

Nakarai, K., Ishida, T. and Maekawa, K., (2006b). "Multi-scale physicochemical modeling of soil-cementitious material interaction." Soils and Foundations, 46(5), 653-663.

Nakarai, K., Watanabe, M., Koibuchi, K. and Kosakowski, G., (2021). "Calcite precipitation at cement-bentonite interface. Part 2: Acceleration of transport by an electrical gradient." Journal of Advanced Concrete Technology, 19(5), 447-461.

Ngala, V. T, and Page, C. L., (1997). "Effects of carbonation on pore structure and diffusional properties of hydrated cement pastes." Cement and Concrete Research, 27(7), 995-1007.

Nindiyasari, F., Fernández-Díaz, L., Griesshaber, E., Astilleros, J. M., Sanchez-Pastor, N. and Schmahl, W. W., (2014). "Influence of gelatin hydrogel porosity on the crystallization of $\mathrm{CaCO}_{3}$." Crystal Growth \& Design, 14(4), 1531-1542.

Palandri, J. L. and Kharaka, Y. K., (2004). " $A$ compilation of rate parameters of water-mineral interaction kinetics for application to geochemical modeling. "U.S. Geological Survey Open File Report, Menlo Park CA: National Energy Technology Laboratory - United States Department of Energy.

Papadakis, V. G., Vayenas, C. G. and Fardis, M. N., (1989). "A reaction-engineering approach to the problem of concrete carbonation." Aiche Journal, 35(10), 1639-1650.

Patel, R., Parrott, L., Martin, J. and Killoh, D., (1985). "Gradients of microstructure and diffusion properties in cement paste caused by drying." Cement and Concrete Research, 15(2), 343-356.

Poonoosamy, J., Curti, E., Kosakowski, G., Grolimund, D., Van Loon, L. R. and Mader, U., (2016). "Barite precipitation following celestite dissolution in a porous medium: A SEM/BSE and mu-XRD/XRF study." Geochimica Et Cosmochimica Acta, 182, 131-144.

Prasianakis, N. I., Curti, E., Kosakowski, G., Poonoosamy, J. and Churakov, S. V., (2017). "Deciphering pore-level precipitation mechanisms." Scientific Reports, 7(1), 13765.

Pusch, R., (1992). "Use of bentonite for isolation of radioactive waste products." Clay Minerals, 27(3), 353-361.
Putnis, A., (2015). "Transient porosity resulting from fluid-mineral interaction and its consequences." Pore-Scale Geochemical Processes, 80, 1-23.

Read, D., Glasser, F. P., Ayora, C., Guardiola, M. T. and Sneyers, A., (2001). "Mineralogical and microstructural changes accompanying the interaction of Boom Clay with ordinary Portland cement." Advances in Cement Research, 13(4), 175-183.

Richardson, M. G., (2002). "Fundamentals of durable reinforced concrete." CRC Press.

RWMC, (2008). "FY2007 report on development of long-term performance assessment method for engineered barrier of TRU radioactive waste repository: evaluation of long-term behavior of engineered barrier." Tokyo: Radioactive Waste Management Funding and Research Center (RWMC). (in Japanese)

RWMC, (2010). "FY2009 Report on development of long-term performance assessment method for engineered barrier of TRU radioactive waste repository: evaluation of long-term behavior of engineered barrier." Tokyo: Radioactive Waste Management Funding and Research Center (RWMC). (in Japanese)

RWMC, (2011). "FY2010 Report on development of long-term performance assessment method for engineered barrier of TRU radioactive waste repository: evaluation of long-term behavior of engineered barrier." Tokyo: Radioactive Waste Management Funding and Research Center (RWMC). (in Japanese)

Savage, D., (2013). "Constraints on cement-clay interaction." In: R. Hellmann, H. Pitsch eds., Proceedings of the Fourteenth International Symposium on Water-Rock Interaction, Wri 14, Avignon France 9-14 June 2013. Elsevier Procedia, 7, 770-773.

Šavija, B. and Luković, M., (2016). "Carbonation of cement paste: Understanding, challenges, and opportunities." Construction and Building Materials, 117, 285-301.

Seigneur, N., Mayer, K. U. and Steefel, C. I., (2019). "Reactive transport in evolving porous media." Reviews in Mineralogy and Geochemistry, 85(1), 197-238.

Sposito, G., Holtzclaw, K. M., Charlet, L., Jouany, C. and Page, A. L., (1983). "Sodium-calcium and sodium-magnesium exchange on Wyoming bentonite in perchlorate and chloride background ionic media." Soil Science Society of America Journal, 47(1), 51-56.

Stack, A. G., (2015). "Precipitation in pores: A geochemical frontier." Pore-Scale Geochemical Processes, 80, 165-190.

Sugita, Y., Fujita, T., Takahashi, Y., Kawakami, S., Umeki, H., Yui, M., Uragami, M. and Kitayama, K., (2007). "The Japanese approach to developing clay-based repository concepts - An example of design studies for the assessment of sealing strategies." Physics and Chemistry of the Earth, Parts $A / B / C, 32(1-7), 32-41$.

Ta, V.-L., Bonnet, S., Senga Kiesse, T. and Ventura, A., (2016). "A new meta-model to calculate carbonation 
front depth within concrete structures." Construction and Building Materials, 129, 172-181.

Tartakovsky, A. M., Redden, G., Lichtner, P. C., Scheibe, T. D. and Meakin, P., (2008). "Mixing-induced precipitation: Experimental study and multiscale numerical analysis." Water Resources Research, 44(6).

Tinseau, E., Bartier, D., Hassouta, L., Devol-Brown, I. and Stammose, D., (2006). "Mineralogical characterization of the Tournemire argillite after in situ interaction with concretes." Waste Management, 26(7), 789-800.

van der Lee, J. and De Windt, L., (2001). "Present state and future directions of modeling of geochemistry in hydrogeological systems." Journal of Contaminant Hydrology, 47(2-4), 265-282.

Van Loon, L. R., Glaus, M. A. and Muller, W., (2007). "Anion exclusion effects in compacted bentonites: Towards a better understanding of anion diffusion." Applied Geochemistry, 22(11), 2536-2552.

Wu, M., Johannesson, B. and Geiker, M., (2012). “A review: Self-healing in cementitious materials and engineered cementitious composite as a self-healing material." Construction and Building Materials, 28(1), 571-583.

Yamaguchi, T., Sawaguchi, T., Tsukada, M., Hoshino, S. and Tanaka, T., (2016). "Mineralogical changes and associated decrease in tritiated water diffusivity after alteration of cement-bentonite interfaces." Clay Minerals, 51(2), 279-287.

Yokozeki, K., Watanabe, K., Sakata, N. and Otsuki, N., (2003). "Prediction of changes in physical properties due to leaching of hydration products from concrete." Journal of Advanced Concrete Technology, 1(2), 161-171.

Yokozeki, K., Watanabe, K., Sakata, N. and Otsuki, N., (2004). "Modeling of leaching from cementitious materials used in underground environment." Applied Clay Science, 26(1-4), 293-308.

\section{Appendix A:}

Chemical composition profiles measured by EPMA are shown in Fig. A1 in addition to main chemical composition shown in Fig. 4.
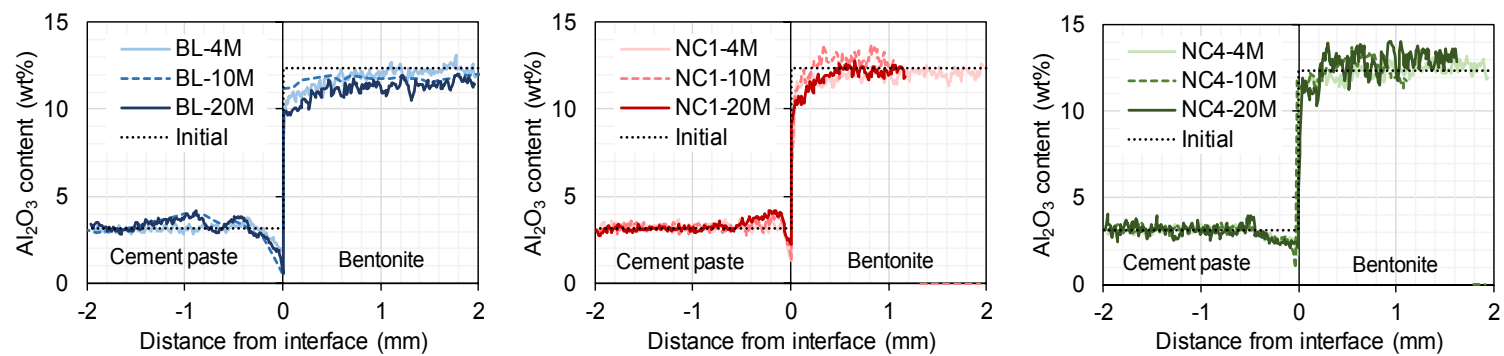

(a) Distribution of sulfate at the cement-bentonite interface
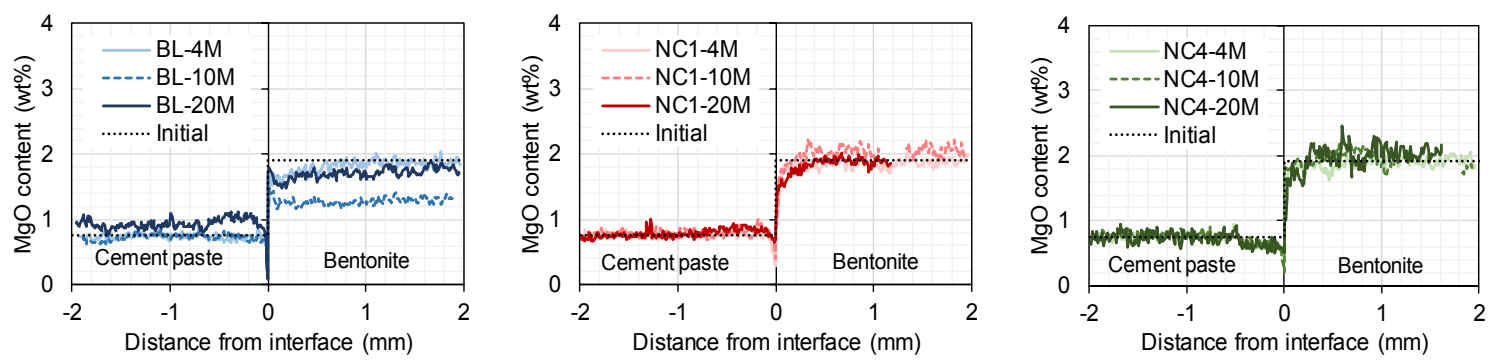

(b) Distribution of magnesium at the cement-bentonite interface
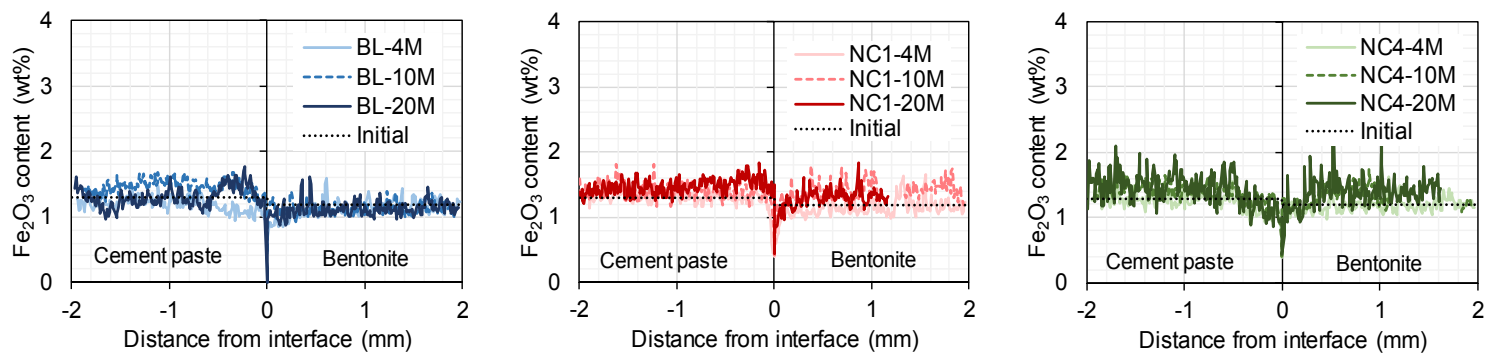

(c) Distribution of iron at the cement-bentonite interface

Fig. A1 Longitudinal chemical composition profile measured by EPMA 


\section{Appendix B:}

All measured XRD intensities of minerals are summarized here. Figs. B1 and B2 show XRD intensities measured at the surface layer of cement paste and bentonite specimens, respectively.

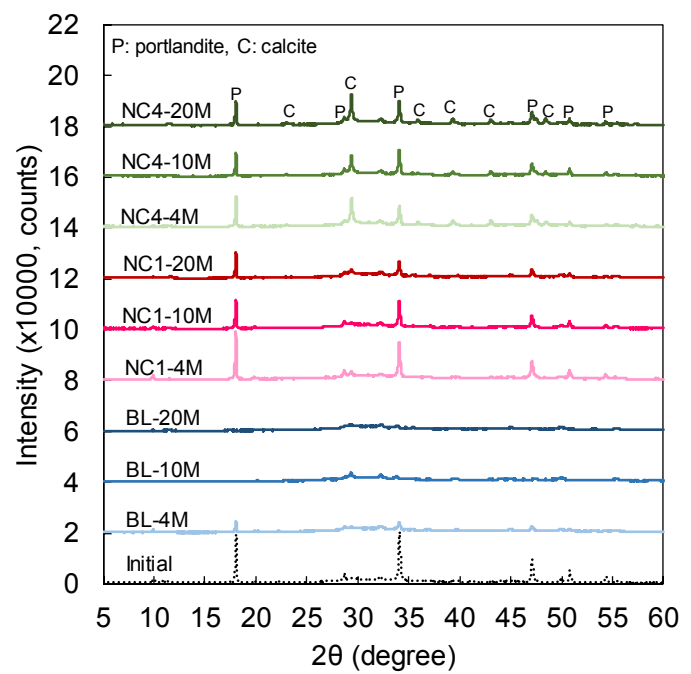

Fig. B1 Changes in XRD intensities of minerals at the surface layer of cement paste specimens before and after immersion tests.

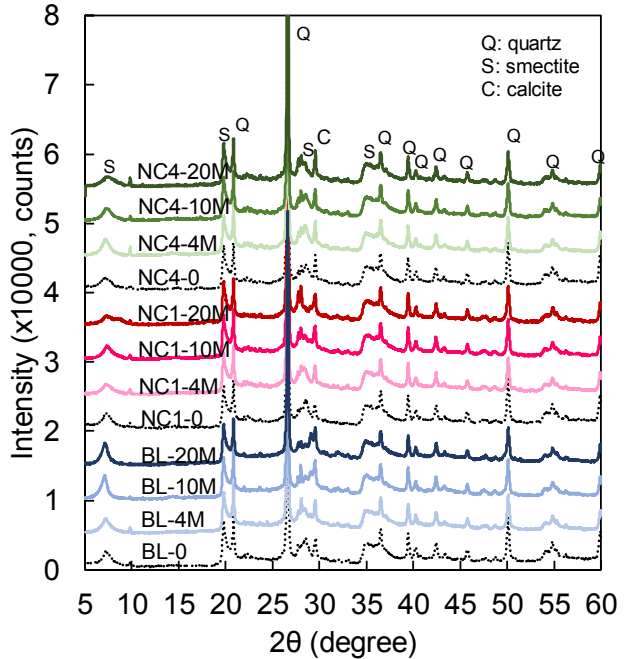

Fig. B2 Changes in XRD intensities of minerals at the surface layer of bentonite specimens before and after immersion tests. 